\title{
Erratum: Addendum of Informed Consent Statements
}

\author{
Endocrinology and Metabolism Editorial Office
}

We have added information about informed consent to two case reports published in the 2015 volume of Endocrinology and Metabolism because we found that a description of informed consent was missing from those reports. Although in its submission guidelines, Endocrinology and Metabolism indicates that information about informed consent should be included in the Methods section, the two papers listed below did not present a description of informed consent. The editorial office verified that the authors received informed consent for the use of the patients' photographs or other information through the publication ethics form that was included when the papers were submitted. Accordingly, the editorial office would like to issue an apology to our readers and to add the corresponding ethics statements to the Methods section of each paper.

1. Multiple Myeloma in a Patient with Acromegaly (Endocrinol Metab 2015;30:110-5).

http://dx.doi.org/10.3803/EnM.2015.30.1.110

\section{Ethics statement}

Informed consent was obtained from the patient for being included in the study.

2. Acromegaly with Normal Insulin-Like Growth Factor-1 Levels and Congestive Heart Failure as the First Clinical Manifestation (Endocrinol Metab 2015;30:395-401).

https://doi.org/10.3803/EnM.2015.30.3.395

\section{Ethics statement}

Informed consent was obtained from the patient for being included in the study.

\section{Endocrinology and Metabolism Editorial Office}

101-2503, Lotte Castle President, 109 Mapo-daero, Mapo-gu, Seoul 04146, Korea

Tel: +82-2-714-2428, Fax: +82-2-714-5103,

E-mail: journal@endocrinology.or.kr
Copyright $\odot 2018$ Korean Endocrine Society

This is an Open Access article distributed under the terms of the Creative Commons Attribution Non-Commercial License (http://creativecommons.org/ licenses/by-nc/4.0/) which permits unrestricted non-commercial use, distribution, and reproduction in any medium, provided the original work is properly cited. 